\title{
Latent inhibition and the preconditioning-conditioning interval*
}

\author{
JAMES P. JAMES \\ Fort Hays Kansas State College, Hays, Kans. 67601
}

With the use of a licking-based CER procedure, latent inhibition effects were reliably demonstrated with rats in acquisition and extinction regardless of whether or not a $1 \cdot \mathrm{h}$ period was interpolated between massed CS preexposure trials and acquisition. Preconditioning CS-alone trials prevented effective conditioning on the first trial, but not on the second.

Preconditioning exposure to a potential CS decreases performance during subsequent conditioning trials. Early experiments on this effect, termed latent inhibition by Lubow \& Moore (1959), focused on its demonstration (e.g., Lubow \& Moore, 1959; Sokolov, 1963). More recently, investigators have turned to manipulating systematically variables thought to influence the effectiveness of latent inhibition (Anderson, O'Farrell, Formica, \& Caponigri, 1969; Anderson, Wolf, \& Sullivan, 1969; Lubow, 1965; Lubow, Markman, \& Allen, 1968; Siegel, 1969a, b, 1970). Latent inhibition has been demonstrated within the CER paradigm for suppression of barpressing (Anderson et al, 1969; May, Tolman, \& Schoenfeldt, 1967) and, in what appears to be a more sensitive CER procedure, suppression of licking (Carlton \& Vogel, 1967; Leaf, Kayser, Andrews, Adkins, \& Leaf, 1968; Lubow \& Siebert, 1969).

Previous experiments on latent inhibition have spaced CS preexposure trials in six or seven daily sessions (Carlton \& Vogel, 1967; Lubow \& Siebert, 1969; Siegel, 1970). The purpose of the present experiment was to investigate the latent inhibition effect as a function of the interval between massed preconditioning CS-alone trials and acquisition. A suppression of licking procedure in

* This research was supported by Grant APA-223 from the National Research Council of Canada. The experimental assistance of Walter Mostoway is greatly appreciated. which the trial by trial course of acquisition could be observed for each group of Ss was used.

SUBJECTS AND APPARATUS

The Ss were 51 naive male rats of the Sprague-Dawley strain, 90-100 days old at the start of the experiment. Two Ss died of a respiratory ailment, and three Ss were discarded for failure to respond during each pre-CS period of Day 1. Data were collected from the remaining 46 Ss. Six measures on Trial 1 and two measures on Trial 3 were discarded for zero pre-CS scores. The animals were individually housed with ad lib food.

The apparatus has been described in detail elsewhere (James \& Mostoway, 1968). Briefly, it consisted of three conditioning chambers with grid floors to present shock. The drinking tube of a water bottle could be remotely presented to, or withdrawn from, Ss. A Grason-Stadler drinkometer (Model E4690A-L) detected tongue contacts with the drinking tube. Scrambled grid shock in each chamber was produced by separate Grason-Stadler (Model E1064GS) shock generators. The CS was white noise from a Grason-Stadler generator (Model 901B).

\section{PROCEDURE}

Once the Ss were placed on water deprivation, they received their entire supply of water in the conditioning chamber. Twenty-four hours following the removal of water bottles from the cages, each $S$ was placed into a conditioning chamber where it could drink from the water tube for a $10-\mathrm{min}$ period. The $\mathrm{Ss}$ were given eight of these $10-\mathrm{min}$ adaptation sessions on successive days.

Preexposure of $\mathrm{CS}$ and conditioning took place on the day following the eighth adaptation session. Three groups received 20 trials of $C S$ preexposure. A fourth group (Group C) was placed in the chamber for an identical period of time but received no $C S$ presentation. The $C S$ was an $82-\mathrm{dB}$ white noise of $10 \mathrm{sec}$ duration. It was presented during preexposure at random intertrial intervals of 45,60 , or $75 \mathrm{sec}$ (mean $=60 \mathrm{sec})$. At the end of this 20-min preexposure period, the water tube was immediately presented to two groups-one preexposed (Group E-0) and one not preexposed (Group C) to the CS-and the conditioning trials were presented during the $10 \mathrm{~min}$ while the drinking tube was accessible. The second and third preexposed groups, Groups E-30 and $E-60$, received the water bottle and conditioning trials 30 and $60 \mathrm{~min}$, respectively, following the final preexposure trial. The first CS-shock pairing was presented $1 \mathrm{~min}$ after the water tube was first presented. The intertrial interval for the three conditioning trials was $2 \mathrm{~min}$. Shock intensity and duration were $0.5 \mathrm{~mA}$ and $0.5 \mathrm{sec}$, respectively. On the next 2 days, extinction trials were conducted similarly to the conditioning trials, except the shock was omitted.

The number of tongue contacts with the drinking tube was recorded for the CS period and for a pre-CS period occurring 10 sec before the CS. Standard suppression ratio scores, where .50 indicates no suppression and 0.00 indicates complete suppression, were used for data analysis.

\section{RESULTS}

Figure 1 shows the mean suppression ratios of the four groups plotted across the three trials of Day 1. Because of excessive variability, the suppression ratios for Days 2 and 3 were computed after pre-CS and CS responses were summed across the three daily trials.

Figure 1 shows that the groups did not differ on the first trial $(\mathrm{F}<1)$. On Trial 2, the groups differed $(F=9.31$, $\mathrm{df}=3 / 42, \quad \mathrm{p}<.001$ ), with Group C suppressing significantly more (New man-Keuls test, $p<.05$ ) in comparison to the groups that received preconditioning exposure to the $\mathrm{CS}$. The suppression ratio scores of each $S$ in Group C decreased from Trial 1 to Trial 2. Groups E-0, E-30, and E-60 showed no significant change in suppression ratio scores across Trials $1-2$. On Trial 3 , the groups again differed significantly $(F=5.84$, d f $=3 / 40, \quad \mathrm{p}<.005)$. By Newman-Keuls test, Group $C$ differed reliably $(p<.05)$ from Groups E-0 


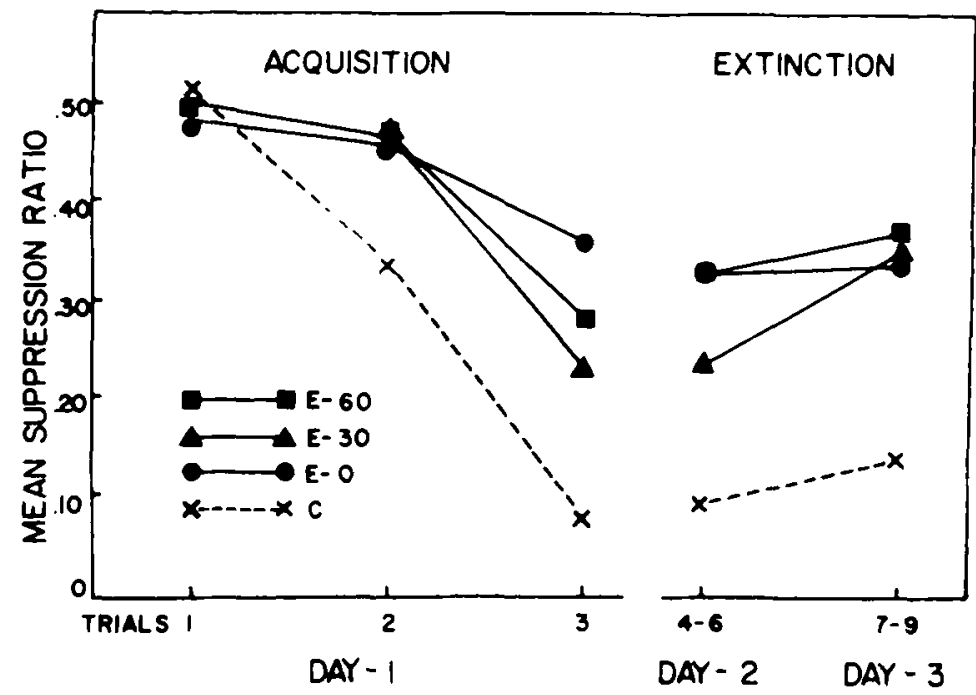

Fig. 1. Mean suppression ratio scores across the three trials of Day 1 and the three-trial blocks of Days 2 and 3.

and E-60; none of the other comparisons was significant. As indicated by Sandler's (1955) "A" statistic, the decrease in suppression ratio scores across Trials 2-3 was significant for all groups (Group C: $\mathrm{A}=.093, \mathrm{df}=11, \mathrm{p}<.001$; Group E-0: $A=.197, d f=11, p<.02$; Group E-30: $A=.202, \mathrm{df}=7, \mathrm{p}<.02$; Group E-60: $A=.154, \quad d f=11$, $\mathrm{p}<.01$ )

Figure 1 shows that, in general, the four groups maintained their relative positions during extinction. There were significant differences $(p<.01)$ on Day $2 \quad(F=4.77)$ and Day 3 $(F=5.40)$.

These data, suggesting that preconditioning exposure to a potential $C S$ decreases subsequent acquisition, are consistent with previous work on suppression of licking (e.g., Carlton \& Vogel, 1967). In the present study, the 20 preconditioning trials of CS-alone appeared to nullify the effect of the first conditioning trial, whether or not a 60-min interval was interpolated between preconditioning CS exposure and conditioning. The second conditioning trial appeared effective, since response suppression increased reliably across Trials $2-3$. The control group that received no preconditioning exposure to the $\mathrm{CS}$, but remained in the conditioning chamber for an interval equal to that of the preexposed groups, showed significant increases in suppression following each CS-shock pairing.

In extinction, the difference between preexposed and non-preexposed groups was maintained and is in accord with the results of certain experiments that found differences in extinction ( Chacto \& Lubow, 1967 , Experiment 2; Lubow, Markman, \& Allen, 1968, Experiment 2), but is in conflict with others that did not (Lubow, 1965; Chacto \& Lubow, 1967, Experiment 1; Lubow, Markman, \& Allen, 1968 , Experiment 1; Schnur \& Ksir, 1969). Lubow \& Siebert (1969) have considered the notion that preexposing the $\mathrm{CS}$ may serve to attenuate possible disruptive effects of the CS during acquisition. This would result in greater initial suppression by the non-preexposed group. The failure to find differences in response suppression on Trial 1 of the present study indicates that the differential performance on subsequent trials was probably not due to differences in the initial disruptive properties of the CS.

The present findings point to a relatively durable inhibitory factor that develops during massed CS-alone preconditioning trials and fails to dissipate over a 1 th period following these CS-alone trials. These results support and extend previous demonstrations (Carlton \& Vogel, 1967; Lubow \& Siebert, 1969; Siegel, 1970) that latent inhibition is retained across a 24-h interval following spaced CS-alone preconditioning trials. Further, in the present experiment, where each S's performance was recorded on each acquisition trial, a rapid decrease in the inhibitory effect following one CS-shock pairing was demonstrated. This is consistent with Carlton \& Vogel (1967), who, testing different $\mathrm{Ss}$ following one, two, or four CS-shock pairings, also found decreasing latent inhibition as a function of number of acquisition trials.
Either the habituation or learned competing-response explanations (Lubow, Markman, \& Allen, 1968) could account for the latent inhibition effect found here. In the preexposed groups, shock presentation of the first trial could serve to dishabituate a habituated orienting response, or it could act as a Pavlovian external inhibitor and decrease the effectiveness of a learned competing response.

\section{REFERENCES}

ANDERSON, D. C., O'FARRELL, T., FORMICA, R., \& CAPONIGRI, $V$. Preconditioning CS exposure: Variation in place of conditioning and of presentation. Psychonomic Science, $1969,15,54-55$.

ANDERSON, D. C., WOLF, D., \& SULLIVAN, P." Preconditioning exposures to the CS: Variation in place of testing. Psychonomic Science, 1969, 14, 233.235.

CARLTON, P. L., \& VOGEL, J. R. Habituation and conditioning. Journal of Comparative \& Physiological Psychology, $1967,63,348-351$.

CHACTO. C.. \& LUBOW, R. E. Classical conditioning and latent inhibition in the white rat. Psychonomic Science, 1967, 9, 135-136.

JAMES, J. P., \& MOSTOWAY, W. W. Conditioned suppression of licking as a function of shock intensity. Psychonomic Science, 1968,13,161-162

LEAF, R. C.. KAYSER, R. J., ANDREWS, J. S., JR., ADKINS, J. W., \& LEAF, S. R. $P$. Block of fear conditioning induced by habituation or extinction. Psychonomic Science, 1968, 10, 189-190.

LUBOW. R. E. Latent inhibition: Effects of nonreinforced preexposure of the CS. Journal of Comparative \& Physiological Psychology, 1965, 60, 454-457.

LUBOW, R. E., MARKMAN, R. E.. \& ALLEN, J. Latent inhibition and classical conditioning of the rabbit pinna response. Journal of Comparative \& Physiological Psychology, 1968, 66, 688-694.

LUBOW, R. E., \& MOORE, A. U. Latent inhibition: The effect of nonreinforced pre-exposure to the conditioned stimulus. Journal of Comparative \& Physiological Psychology, 1959, 52, 415-419.

LUBOW, R. E., \& SIEBERT, L. Latent inhibition within the CER paradigm. Journal of Comparative \& Physiological Psychology, 1969, 68, 136-138.

MAY, R. B., TOLMAN, C. W., \& SCHOENFELDT, M. G. Effects of pretraining exposure to the CS on conditioned suppression. Psychonomic Science, 1967, 9, 61-62.

SANDLER, J. A test of the significance of the difference between the means of correlated measures, based on a simplification of the Student's t. British Journal of Psychology, 1955, 46, 225-226.

SCHNUR, P., \& KSIR, C. J. Latent inhibition in human eyelid conditioning. Journal of Experimental Psychology, $1969,80,388-389$.

SIEGEL, S. Effect of CS habituation on eyelid conditioning. Journal of Comparative \& Physiological Psychology, 1969a, 68, 245-248.

SIEGEL, S. Generalization of latent inhibition. Journal of Comparative \& Physiological Psychology, 1969b, 69, 157-159.

SIEGEL, S. Retention of latent inhibition. Psychonomic Science, 1970, 20, 161-162.

SOKOLOV, E. N. Perception and the conditioned reflex. Oxford: Pergamon, 1963. 